\title{
Plasticidade Sináptica: Natureza e Cultura Moldando o Self
}

\author{
Synaptic Plasticity: Nature and Nurture Shaping the Self
}

\author{
Angela Donato Oliva*, $a$, Gisele P. Dias ${ }^{b} \&$ Ricardo A. M. Reis ${ }^{b}$ \\ ${ }^{a}$ Universidade do Estado do Rio de Janeiro \& ${ }^{b}$ Universidade Federal do Rio de Janeiro
}

\begin{abstract}
Resumo
O cérebro em desenvolvimento segue inicialmente um plano genético, estabelecido pela história evolutiva da espécie humana, porém é muito sensível ao ambiente. Estímulos ambientais modificam a estrutura dos circuitos neurais, refinando e tornando as sinapses, alvo de ação dos neurotransmissores, mais eficientes por meio de atividade elétrica e mensageiros químicos. O objetivo desse estudo é discutir teoricamente como a plasticidade e a especificação prévia de sistemas cerebrais coexistem no cérebro. Conclui-se destacando a importância de integrar aspectos de aprendizagem social e da biologia na construção e refinamento das variadas habilidades humanas.
\end{abstract}

Palavras-chave: Aprendizagem; especificação neural; genes; experiência; interação.

\begin{abstract}
The developing brain requires a genetic plan, established by the evolutionary history of human species, but it is also very sensitive to the surrounding environment. Environmental stimuli can modify the structure of neural circuits, refining and making synapses, which are the target of neurotransmitters, more efficient by electrical activity and chemical messengers. The aim of the present study is to discuss theoretically how both plasticity and previous specification of brain systems coexist in the brain. The conclusion shows the importance to integrate aspects of social learning and biology in building and refining the various humane skills.

Keywords: Learning; neural specification; genes; experience; interaction.
\end{abstract}

No final do século XX e início do XXI, os avanços nas neurociências mostraram evidências favoráveis à plasticidade neural. Indicaram a neurogênese no cérebro adulto, as bases moleculares da memória e da aprendizagem e a existência de milhares de sistemas trabalhando de forma integrada (Jones, 2000). Atualmente, cada vez mais se busca identificar nas estruturas cerebrais o que se observa em termos comportamentais. Contudo, questões sobre como as redes sinápticas estão organizadas e como exatamente funcionam ainda estão longe de serem totalmente compreendidas.

Estudos sobre o desenvolvimento formulam perguntas sobre como as estruturas cerebrais iniciais e as conexões sinápticas que vão sendo estabelecidas com as experiências possibilitam os inúmeros comportamentos e processos cognitivos humanos (Karmiloff-Smith, Plunkett, Johnson, Elman, \& Bates, 1998; Lametti \& Mattar, 2006; Quartz \& Sejnowski, 1997, entre outros). Eles indicam que as interações humanas criam as conexões neurais a partir das quais a mente emergiria. Sem essa experiência crucial de relacionamento com os outros o desenvolvimento ficaria seriamente comprometido (Rochat \& Striano, 1999; Rovee-

\footnotetext{
* Endereço para correspondência: Universidade do Estado do Rio de Janeiro, Instituto de Psicologia, Rua São Francisco Xavier, 524, $10^{\circ}$ andar, Bloco F, sala 1005, Maracanã, Rio de Janeiro, RJ, Brasil, CEP 20550-900. E-mail: angeladonatoliva@uol.com.br
}

Collier, 2000). As interações sociais são de natureza simbólica, como destaca Mead (1934) e modificam as estruturas cerebrais (LeDoux, 2002). A questão de como a mente emerge do cérebro em desenvolvimento envolve inúmeros outros problemas (cf. Ramachandran, 2004). Como a consciência surge em meio às redes neurais? Como a atividade neural origina o sentido de sermos seres conscientes? A experiência do self seria resultante do funcionamento cerebral global ou seria resultante da atividade de determinados circuitos cerebrais interligados? Qual seria a natureza do self e qual a relação deste com o cérebro? Temos acesso aos nossos estados mentais e em que medida isso difere do que podemos "ler" sobre o estado mental dos outros? Como um impulso elétrico ativa proteínas e neurotransmissores configurando uma ação intencional? Como pensar a relação entre plasticidade cerebral e modularidade? Esta última questão tem sido bastante discutida por diferentes perspectivas (para uma revisão completa vide Oliva et al., 2006; Seidl de Moura, 2005).

Recentes estudos nas neurociências possibilitam um entendimento cada vez mais preciso sobre como os circuitos neurais incorporam e consolidam experiências passageiras em eventos duradouros de nossa memória (Kandel, 2001). A importância dessas investigações tem sido a de indicar a complexa relação que existe entre a organização de estruturas supra-moleculares envolvidas com as sinapses e os repertórios comportamentais. Estudos envolvendo a neurobiologia do desenvolvimento apresentaram um avanço 
considerável nas últimas décadas em várias áreas relacionadas com a geração, proliferação, sobrevida e organização de neurônios (Carlén, Meletis, Barnabé-Heider, \& Frisén, 2006; Jessell \& Sanes, 2000, Zito \& Svoboda, 2002). Resta compreender como estão relacionados com aspectos cognitivos e comportamentais, considerando a múltipla interação dos planos biológico e social. Ou seja, como as experiências individuais permitem a constituição da experiência de self no mundo social.

O self pode ser definido, de maneira geral, como a representação mental da experiência pessoal consciente, que inclui processos de pensamento e um corpo físico (Gazzaniga \& Heatherton, 2005). Possuímos o sentido de termos nossas próprias experiências em uma continuidade integrada ao longo do tempo e da história. Sabemos quem somos, o que nos caracteriza como indivíduos e nos diferenciamos dos outros. Por volta dos dezoito meses, desenvolve-se o senso inicial de self, como mostra o estudo clássico de Lewis e Brooks-Gunn (1979) sobre auto-reconhecimento diante de um espelho. Sedikides e Skowronski, (1997) distinguem alguns níveis de self, sendo que a maioria dos animais experienciariam o self mínimo. Destacam esses autores que o self simbólico (self narrativo) seria uma adaptação relativamente recente das pressões evolutivas e seria único para os humanos. James (1890/ 1950) e Mead (1934) diferenciaram o self como o "eu" que conhece, escolhe, planeja e o self como o objeto que é conhecido ou objeto de atenção que é conhecido como autoconsciência. Para esses autores, o bebê nasce com um senso mínimo de self que se desenvolve por intermédio das interações sociais. Autores (Gazzaniga \& Heatherton, 2005; Sedikides \& Skowronski, 1997) destacam crescente número de evidências empíricas que apontam para o papel dos lobos frontais na autoconsciência. Essas estruturas seriam importantes para a memória e para a interpretação de eventos, além de ser compatível com o fato de que os lobos frontais seriam uma adaptação evolutiva recente e estariam pouco desenvolvidos no nascimento (Rapoport \& Gogtay, 2008). Ponderam que a ausência de autoconsciência simbólica em animais não-humanos e bebês pequenos poderia ser devido ao fato de o self se desenvolver com os lobos frontais.

Assume-se aqui uma perspectiva interacionista, pois supõe-se que a individualidade é construída a partir da interação de uma identidade genética com experiências sensoriais e cognitivas. James (1890/1950) destaca que o self de cada um modifica-se de acordo com o contexto social. Estudos nas neurociências (LeDoux, 2002) vêm tentando conectar o social e o biológico nas explicações sobre os processos humanos. O foco das visões que buscam essa integração é saber como o nosso cérebro registra, organiza e interpreta as experiências que são integradas em um processo dinâmico e coeso, no qual passado, presente e futuro coexistem. Esse entendimento pode contribuir para explicar características de personalidade, formas de interagir com os outros, modos de construir, transmitir e internalizar valores sociais.

\section{Cérebro e Ambiente: Uma Relação Interativa}

Para a psicologia evolucionista, o cérebro humano é um aparato computacional complexo no qual diversos dispositivos especializados funcionam de maneira integrada (Duchaine, Cosmides, \& Tooby, 2001). As investigações da abordagem evolucionista procuram mapear os programas cognitivos - a circuitaria neural - selecionados ao longo da história evolutiva. Isso corresponderia a identificar, em alguns comportamentos, o substrato da "natureza humana", aqui entendida como a arquitetura neural e computacional típica da nossa espécie e que caracteriza a mente e o cérebro dos seres humanos com as regras de processamento de informações (Cosmides \& Tooby, 2000).

Esses estudos lançam hipóteses sobre o funcionamento da arquitetura mental, mas não respondem a perguntas sobre como fatores genéticos e ambientais interagem na organização cerebral. Em outras palavras, não se sabe como a plasticidade das estruturas neurais ou um pré-estabelecimento genético das mesmas podem explicar a configuração do sistema cerebral ao longo do desenvolvimento. Nos circuitos sinápticos é integrada a informação entre estímulos ambientais e respostas do organismo. A plasticidade cerebral permite adaptações nos variados contextos sociais e faz parte da arquitetura neural da espécie (Oliva et al., 2006). Essa característica biológica não significa inflexibilidade no âmbito social, ao contrário, é o que possibilita as trocas sociais.

\section{Formação do Cérebro: Aspectos Biológicos}

O cérebro humano é composto por quase cem bilhões de neurônios intrinsecamente conectados que permitem desde a regulação de funções básicas, como a respiração, até tarefas elaboradas, tais como acreditar em uma idéia (LeDoux, 2002). Todas as condutas humanas, sejam elas explícitas ou implícitas, são possibilitadas por essas redes neurais. Contudo, os neurônios apenas não são suficientes para explicar essas condutas. A experiência de cada um parece unir as dimensões social e biológica. Psicólogos e biólogos têm procurado uma forma mais integrada de abordar essa questão.

Nos seres humanos, grande parte dos neurônios é formada em um período que antecede o nascimento. $\mathrm{O}$ pico de produção pode chegar a aproximadamente 250.000 neurônios por minuto (Cowan, 1979). Esse processo é controlado por diversos fatores que se difundem no tubo neural. Os genes atuam na produção de proteínas que, por sua vez, regulam a produção dessas células. Descrito dessa forma, pode parecer que o desenvolvimento embrionário depende unicamente de um comando genético. Entretanto, fatores epigenéticos desempenham um papel crucial nesse processo (LeDoux, 2002). Por exemplo, se houver ingestão de álcool, drogas (Kotch \& Sulik, 1992) ou agentes antidepressivos (Leonardo \& Hen, 2006) no período inicial da gestação, a produção neural sofre alterações e podem ocorrer quadros de anencefalia, espinha bífida ou comportamentos de ansiedade nos filhos (Leonardo \& Hen, 2006). 
Porém, nem sempre álcool ou drogas, como cocaína ou anfetamina, produzem tais anomalias e nem sempre estas são decorrentes da ingestão dessas substâncias. Um dos objetivos dos estudos psico-biológicos em curso é destacar a importância de entender como processos que obedecem a mecanismos físicos e químicos de dimensão molecular microscópica interagem com dinâmicas sociais, culturais e históricas, de dimensão macroscópica; como esses fenômenos integrados a partir de estudos em seres humanos e em modelos animais apontam para diferentes papéis da experiência ao longo do desenvolvimento de uma pessoa. Essa influência parece ser crucial nos chamados períodos sensíveis, nos quais os circuitos neurais estariam mais sensíveis a mudanças. Um outro ponto que alguns teóricos (Johnston, 2004; Kandel, 2000; Ledoux, 2002) têm defendido, a partir de evidências empíricas, é que para que seja possível a ocorrência de um comportamento, várias estruturas devem participar de maneira integrada. Uma habilidade parece depender de um conjunto de estruturas articuladas e isso pode funcionar como uma forma de proteção (Johnston, 2004). Segundo este autor, se uma estrutura for lesionada, a função pode ser mantida por outras que também participam, em graus diferentes, da tarefa. Se apenas uma estrutura possibilitasse uma função, o risco de perda seria maior para o sistema cerebral.

\section{Formação do Cérebro: A Busca de Integração entre os Planos Biológico e Social}

$\mathrm{Na}$ atualidade existem poucas evidências de que o cérebro humano de um recém-nascido possa ser comparado a uma tabula rasa à espera de ser preenchido pela experiência (Cosmides \& Tooby, 2000; Pinker, 2002; Seidl de Moura, 2005). Há comportamentos em bebês que parecem resultar de elaborados programas estabelecidos pela evolução. Esses programas seriam automáticos, não aprendidos e possibilitariam respostas complexas, rápidas e eficientes, o que sustenta a hipótese da especificidade neural e dos módulos mentais esculpidos pela seleção natural.

No entanto, não parece defensável a posição de que os comportamentos seriam apenas geneticamente determinados, resultantes exclusivamente de mecanismos ou programas biológicos que nos impelem a agir, pensar e sentir de um modo particular. Nem é isso que os defensores de módulos mentais pré-programados alegam. Ao contrário, a tendência atual, que tem recebido contribuições importantes das neurociências, sustenta que os circuitos cerebrais emergem e são moldados a partir de uma combinação de influências genéticas e ambientais (LeDoux, 2002; Ridley, 2004). O antigo debate natureza e cultura tem sido substituído pela questão de como ambos - interagindo nas experiências dos sujeitos - contribuem para a construção do cérebro e para o estabelecimento de sinapses (LeDoux, 2002; Ridley, 2004). Os seres humanos têm a capacidade biológica (natureza) de construir e comunicar para os outros as coisas que aprenderam no âmbito social (cultura). Deve-se considerar tanto a marca que a experiência deixa em nosso cérebro quanto a herança ancestral carregada pelos genes que influenciam a organização funcional e es- trutural de nosso cérebro (LeDoux, 2002). A modelagem das conexões sinápticas depende tanto dos genes quanto da experiência (LeDoux, 2002).

A construção da intersubjetividade, o desenvolvimento do self, a consciência de si e dos outros, o conhecimento social, a capacidade de entender as intenções alheias, entre tantas outras capacidades, só se constituem na interação e pela interação com os outros (Ramachandran, 2004). Não seria possível um ser humano se desenvolver como tal se fosse criado em isolamento social (Rochat \& Striano, 1999; Rovee-Collier, 2000). Pode-se dizer, a partir desses estudos, que a condição de possibilidade é biológica e a condição material ou a forma específica de nos tornarmos pessoas de um modo particular é modulada pela dimensão social.

Se os organismos não são uma tábula rasa, ou seja, se existem programas que predispõem a agir de certas maneiras, temos a possibilidade teórica de o cérebro apresentar módulos especificados. Com isso deparamo-nos com o problema de explicar a grande adaptabilidade do cérebro frente aos variados ambientes sociais e culturais ao longo da história. Como é possível a plasticidade em um sistema composto por programas que levam o organismo a agir de determinado modo?

\section{Plasticidade Sináptica e o Desenvolvimento do Cérebro}

$\mathrm{O}$ termo plasticidade sináptica refere-se às respostas adaptativas do sistema nervoso (SN) frente aos estímulos percebidos. A maioria dos sistemas no cérebro são plásticos, ou seja, são modificados com a experiência, o que significa que as sinapses envolvidas são alteradas por estímulos ambientais captados por alguma modalidade de percepção sensorial. O conceito de plasticidade sináptica foi definido há mais de um século pelo fisiologista Charles Sherrington e é uma propriedade essencial do desenvolvimento e uma das principais funções cerebrais. Em concordância com o conceito de plasticidade, LeDoux (2002) sustenta que o cérebro é muito sensível ao ambiente, e isso não é incompatível com um funcionamento possibilitado (mas não determinado) pelos genes. A experiência permite a aquisição de conhecimentos e de informações pelo SN provocando alterações anatômicas em diversos locais do encéfalo e essas alterações modificam a intensidade das conexões entre as células.

As modificações sinápticas não se restringem a algum período do desenvolvimento e ocorrem em todos os momentos em que há aprendizagem (Kandel, 2000). O cérebro adulto se adapta constantemente aos estímulos e essa plasticidade não se manifesta apenas em comportamentos de aprendizagem e memória que indicam a base biológica da individualidade. Essas mudanças dinâmicas são visíveis no processamento do $\mathrm{SN}$ e podem ser estudadas de forma mais consistente no principal local que envolve a troca de informações no cérebro: a sinapse.

\section{Sinapse e Plasticidade}

Depois de um século de descobertas, as sinapses foram inicialmente agrupadas em elétricas e químicas, caracteri- 
zadas tanto pelo fluxo de correntes elétricas quanto pela liberação de mediadores químicos chamados de neurotransmissores (Kandel, 2000). Há também sinapses eletro-químicas, onde coexistem diversos tipos de moléculas sinalizadoras. A sinapse pode ser fisicamente representada por uma fenda nanométrica separando duas estruturas especializadas num terminal pré-sináptico que irá influenciar (e poderá ser influenciado por) uma região pós-sináptica. Estima-se que cada um dos bilhões de neurônios que formam o SN é capaz de formar milhares de sinapses individuais, excitatórias, inibitórias ou regulatórias, aumentando a complexidade do SN (Kandel, 2000). Santiago Ramón y Cajal, em 1896, foi o responsável pela introdução do conceito de polarização dinâmica, sugerindo que os neurônios apresentavam-se assimétricos em sua estrutura, envolvidos com o fluxo diferenciado de informação de circuitos funcionais no $\mathrm{SN}$.

Hebb (1949) previu uma forma de plasticidade sináptica decorrente da sincronia dos neurônios pré e pós-sinápticos. $\mathrm{O}$ disparo elétrico em alta freqüência levaria, por associação, ao fortalecimento das respostas sinápticas, caracterizando o processo de aprendizagem. Essa previsão foi constatada algumas décadas após com a descoberta do fenômeno de potenciação de longo prazo, LTP (Long Term Potentiation) descrita em sinapses hipocampais de coelhos no estudo de Bliss e Lomo (1973). O fenômeno de LTP é um processo fisiológico no qual o fortalecimento das conexões sinápticas é observado entre os neurônios de várias regiões do SN após uma ativação intensa (estímulo tetânico). Suas propriedades são associação, cooperação e especificidade, que são fundamentais para os processos de codificação, armazenamento, consolidação e recuperação da memória (Kandel, 2000). Hebb (1949) não acreditava que as associações ficassem restritas a sinapses, mas sim que os neurônios fizessem parte de uma rede (ensemble) de células capaz de propagar para outros sistemas a informação captada por essas conexões sinápticas. Assim, o comportamento dependeria essencialmente da forma pela qual os neurônios estão conectados uns aos outros em circuitos (LeDoux, 2002). As várias etapas do desenvolvimento do cérebro humano levam um tempo considerável para acontecer e os diferentes circuitos seguem eventos interativos em diferentes momentos, construindo nossas respostas e o nosso repertório mental de forma gradual e única desde a infância (Jessell \& Sanes, 2000). Nosso self é fruto das experiências sociais e do legado genético (LeDoux, 2002).

\section{Espinhas Dendríticas, Aprendizagem e Memória}

Com novas técnicas de imagem Matsuzaki, Honkura, Ellis-Davies e Kasai (2004) estudaram a indução de LTP em pequenas estruturas compartimentalizadas denominadas espinhas dendríticas. De acordo com esses autores, as espinhas estão localizadas nos dendritos de neurônios excitatórios do hipocampo e do córtex e são elementos-chave para referendar mecanismos de aprendizagem. Nessas estruturas ocorrem as características fundamentais da LTP e da memória: especificidade, associação, detecção coincidente hebbiana e dependência de uma atividade pré-pós sináptica, convergindo informação nas células piramidais do hipocampo e do córtex (Matsuzaki et al., 2004). Essas pequenas estruturas assumem diversas morfologias que muitas vezes refletem o grau de amadurecimento e de interação com alvos neurais (Matus, 2000). O estudo de Matsuzaki et al. (2004), indica ainda que o fenômeno da LTP pode induzir mudanças físicas nas espinhas dendríticas. Os autores utilizaram neurônios do hipocampo de roedores com o auxílio de um microscópio multi-fotônico para revelar mudanças sutis no volume das espinhas dendríticas. Mediante estímulos que geravam pulsos tetânicos de alta freqüência (tais quais os necessários para gerar a LTP), os resultados indicaram que as espinhas individuais seguem o postulado de Hebb em paradigmas de aprendizagem. Os autores concluíram ainda que as pequenas espinhas constituem os locais preferenciais para a indução da LTP, enquanto as espinhas maiores representam traços físicos de memórias já registradas. Existem diversos locais no cére-bro para armazenamento de memórias. As espinhas den-dríticas são encontradas não apenas no hipocampo e no córtex, locais associados com memórias explícitas (para fatos e eventos), mas também em alguns circuitos envolvendo a amígdala e os gânglios da base (LeDoux, 2002). Essas regiões estão envolvidas com memórias implícitas (respostas emocionais e alguns reflexos) e têm recebido uma enorme atenção nos últimos anos (LeDoux, 2002).

\section{Darwinismo Neural}

Nos mais diversos sistemas neurais, as conexões precisas emergem de padrões inicialmente imprecisos dos contatos sinápticos (Quartz \& Sejnowski, 1997). A complexidade dos circuitos é gerada durante o desenvolvimento, inicialmente por um processo genético e, em seguida, é elaborada a partir de uma intensa interação com o ambiente (Quartz \& Sejnowski, 1997). Entender a atuação do ambiente na configuração dos circuitos sinápticos é fundamental para uma compreensão da cognição em termos neurais, que pode ser traduzida por duas hipóteses no debate natureza e cultura: a hipótese da seleção e a da instrução.

Uma das vertentes que busca responder às hipóteses sobre o papel da atividade neural iniciada pelo ambiente é denominada selecionismo neural (LeDoux, 2002). Tal perspectiva supõe um conjunto pré-existente de conexões sobre o qual as experiências atuariam. $\mathrm{O}$ resultado disso seria uma seleção de circuitos que atenderiam às demandas ambientais. Para sustentar essa hipótese é necessário supor três princípios básicos: (a) exuberância; (b) uso e (c) subtração. O princípio da exuberância postula que o sistema inicialmente apresenta um número superior de sinapses do que as que serão mantidas nas etapas do desenvolvimento. Subtrair as conexões não selecionadas (ou não ativadas pela experiência) das que foram ativadas resultaria naquilo que somos. O segundo princípio diz respeito ao uso: apenas sinapses ativas são mantidas. $O$ terceiro princípio defende que as conexões inativas são eliminadas. Edelman (2003) é um dos principais defensores contempo- 
râneos da hipótese de que o desenvolvimento e a organização das funções superiores cerebrais podem ser explicados em termos da seleção de grupamentos neurais, criando o termo Darwinismo Neural. Essa perspectiva afina-se com as contribuições de autores da psicologia evolucionista (Cosmides \& Tooby, 2000; Pinker, 2002), que pressupõem a existência de programas mentais estabelecidos na evolução. O darwinismo neural precisa contar com a emergência de um número muito grande de conexões que surgem em diferentes períodos do desenvolvimento para dar conta da diversidade ambiental.

\section{Construtivismo Neural e Tabula Plástica: Hipótese da Instrução Neural}

A outra vertente que busca explicar o papel da atividade neural iniciada pelo ambiente, defende uma posição diametralmente oposta à anterior. Ao contrário do selecionismo, a instrução constitui-se como uma abordagem construtivista do crescimento neural. A questão de como ocorre o desenvolvimento do cérebro e de como este faz emergir representações mentais baseia-se na idéia de que as representações corticais são construídas a partir da interação entre mecanismos de crescimento e atividade neurais estimulada pelo ambiente (Quartz \& Sejnowski, 1997). Enquanto as propostas do selecionismo neural defendem a idéia de que haveria no cérebro um potencial para as capacidades humanas a partir do qual os processos cognitivos emergiriam como resultantes da seleção de conexões sinápticas, o chamado construtivismo neural enfatiza bastante a plasticidade cortical. Para essa perspectiva, o neocórtex dos mamíferos não obedeceria a um programa de organização pré-estabelecido. A abordagem enfatiza a capacidade do organismo de adaptar-se flexivelmente (ou plasticamente) aos diferentes ambientes e alega que um programa pré-estabelecido implicaria no problema de explicar como a plasticidade seria possível. Neste contexto, as estruturas representacionais são progressivamente adicionadas ao aparato cognitivo, conforme o organismo interage com o meio (Quartz \& Sejnowski, 1997). Um estudo de Johnston (2004) mostra que lesões em áreas envolvidas no processamento da linguagem causam um pequeno prejuízo no cérebro de uma criança, mas severos problemas no uso da linguagem em um adulto. Para esse autor, isso seria indicativo de plasticidade cortical e estaria em concordância com os princípios construtivistas. Ao que parece, no início da vida, antes que os circuitos estejam estruturados, áreas primariamente não envolvidas no processamento lingüístico poderiam assumir tal função.

\section{Hipótese de Modularização}

Todo esse debate tem servido para colocar em foco questões que podem contribuir para o entendimento da mente. Não há consenso entre os autores em relação ao problema de considerar o cérebro como um órgão completamente plástico (Johnston, 2004; Quartz \& Sejnowski, 1997) ou pré-formado em termos de estruturas funcionais (Edelman,
2003; Pinker, 2002). Há lacunas sobre como seria o processo de especialização das estruturas neurais. Uma contribuição importante para entender essa questão é a suposição formulada por Karmiloff-Smith (1992). Para ela, no início do desenvolvimento, seria admitido um número mínimo de estruturas pré-especificadas, o menor possível para fazer o sistema mental funcionar e interagir com o ambiente. O que propõe é um mecanismo de crescente modularização, um processo gradual, decorrente da aprendizagem e do desenvolvimento e que culmina em estruturas altamente especializadas. Um dos pontos que ressalta é que a completa ausência de especificações esbarraria no problema de "o que se deve assimilar" diante de uma infinidade de estímulos ambientais. Ao mesmo tempo, uma grande quantidade de estruturas mentais previamente especificadas levaria ao impasse de como poderíamos nos adaptar às diferentes circunstâncias. Para a autora, os selecionistas precisam explicar como é possível a plasticidade em um sistema com viés de forte especificação.

\section{A Atividade Neural Possibilitando a Plasticidade}

O papel da atividade elétrica é essencial para a regulação do desenvolvimento neural e ocorre pela ativação de receptores sensoriais especializados por meio de estímulos físicos e pela ativação espontânea das células neurais, observada em estágio precoce no qual os sistemas sensoriais ainda não estão desenvolvidos. O refinamento das conexões sinápticas parece depender dessas formas de atividade. Katz e Shatz (1996) demonstraram a presença de atividade espontânea em várias partes da retina e do tálamo embrionários de ratos, mesmo na ausência de qualquer experiência visual. Mostraram ainda que alterações genéticas que impedem essa atividade anterior à experiência resultam em perdas visuais permanentes.

O papel exato da atividade elétrica é algo ainda debatido, mas parece ter efeitos diferenciados no desenvolvimento. Durante o período crítico, por exemplo, consolida circuitos e sua ausência pode ter efeitos irreversíveis. O cerne dessa discussão, como já foi salientado, é se a atividade neural tem a função de ajudar a criar as conexões (construtivismo) ou de selecionar, a partir de um conjunto inicial, conexões estabelecidas intrinsecamente (selecionismo).

Essa discussão relaciona-se com os limites e o alcance das explicações baseadas nos princípios da plasticidade cerebral ou aquelas fundamentadas em sistemas mentais específicos e pré-estabelecidos para a espécie. Estudos empíricos corroboram as duas visões. Há tanto evidências favoráveis à plasticidade quanto aos programas prévios. $\mathrm{O}$ que pode e o que não pode ser explicado por esses princípios? O que se ganha em termos de compreensão ao se supor a co-existência de plasticidade e programas previamente estabelecidos? O cérebro, por ser um órgão extremamente complexo, poderia funcionar de acordo com esses dois princípios, não de maneira a um anular o outro, mas de modo que um atue onde o outro não possa fazê-lo com eficiência e economia. 
Isso ficaria consoante com perspectivas mais contemporâneas (Lamprecht \& LeDoux 2004), que indicam que funcionamos de maneiras diferentes em função dos ambientes e estímulos aos quais somos submetidos. Há momentos nos quais ações mais automáticas precisam ocorrer e os sistemas responsáveis por isso parecem funcionar de acordo com mecanismos preestabelecidos. Contudo, um sistema menos automático e mais preciso entraria em ação a seguir para corrigir eventuais respostas não adaptativas aos contextos.

\section{Perspectiva Evolucionista e Resultados de Estudos Empíricos}

A construção de redes sinápticas ocorre de maneira semelhante para todos os sujeitos da espécie. Esse padrão, que desde a origem é interativo, pode ser explicado como decorrente de um longo processo evolutivo. A suposição evolucionista é a de que as respostas que solucionaram problemas de sobrevivência e de reprodução nos ancestrais caçadores-coletores deixaram marcas em nossos cérebros. Essa hipótese tem sido testada, indiretamente, através de estudos com bebês bem pequenos (Duchaine et al., 2001). Pesquisas sobre competências iniciais em recém-nascidos servem de evidência empírica para fundamentar hipóteses sobre mecanismos de refinamento do cérebro através da seleção natural (Duchaine et al., 2001; Oliva, 2004; Spelke, 2000).

Inúmeras capacidades de bebês são registradas na literatura e estes mesmos estudos empíricos sugerem que elas não parecem ser decorrentes de mecanismos tradicionais de aprendizagem, tal a sua complexidade (Oliva, 2004; Oliva et al., 2006; Seidl de Moura \& Ribas, 2004). Recémnascidos olham por mais tempo para figuras que se assemelham à face humana (Turati, Simion, Milani, \& Umiltà, 2002); entre quatro e seis meses observam por período de tempo maior os eventos que contrariam certos fenômenos físicos ou eventos impossíveis de ocorrer em condições naturais. Os bebês olham por mais tempo uma bola em movimento que transpõe um anteparo sólido do que a bola que pára diante do mesmo, caracterizando um evento físico possível (Baillargeon, 1995; Spelke, 2000); percebem profundidade (Baillargeon, 1995); discriminam entre os fonemas (Dupoux, Pallier, Kakehi, \& Mehler, 2001) e por volta do oitavo mês perdem parte dessa capacidade que se ajusta aos fonemas utilizados à língua na qual o bebê está exposto, assemelhando-se à discriminação fonética exibida pelo adulto. Distinguem, com poucas horas de vida, o toque proveniente de própria estimulação e o toque proveniente de outrem (Rochat \& Striano, 1999). Bebês de seis semanas imitam expressões faciais que observam em um modelo (Meltzoff \& Moore, 1994), mesmo após um intervalo de 24 horas. Bebês de dois meses olham por mais tempo faces consideradas atraentes (Slater et al., 1998). Apresentam preferência pela voz materna (Rovee-Collier, 2000). Por volta dos dois meses reagem emocionalmente quando expectativas sobre as reações dos outros são quebradas (Rochat \& Striano, 1999). As pesquisas sobre o desenvol- vimento inicial descortinam essas e outras habilidades, mas é importante que investigações empíricas continuem sendo realizadas para melhorar o entendimento sobre esses comportamentos iniciais. Levando em consideração os argumentos de Spelke (2000), ressalta-se que a enorme capacidade que os bebês exibem para aprender depende fundamentalmente de estruturas cerebrais pré-existentes para perceber o mundo.

Teóricos evolucionistas tais como, Tooby e Cosmides (1995) consideram que a maneira pela qual as crianças apresentam certas capacidades cognitivas precoces se explica pela existência de uma natureza humana universal, constituída de mecanismos psicológicos, produtos da evolução. Esses mecanismos seriam adaptações resultantes de um processo de seleção natural ao longo do tempo evolutivo. Tarefas extremamente complexas, tais como o reconhecimento de faces, são executadas facilmente por bebês, sem necessidade de instrução formal. Como explicar essas habilidades sem auxílio de mecanismos previamente configurados no cérebro? Ao mesmo tempo, como considerar as possibilidades da plasticidade em um cérebro pré-especificado pela evolução?

\section{Considerações Finais}

Há perguntas formuladas por psicólogos e biólogos e que permanecem ainda sem uma resposta satisfatória. Não se sabe exatamente como as células no desenvolvimento embrionário tornam-se neurônios e como os axônios de todas essas células encontram seus alvos corretos. Também se desconhece qual a parcela de influência dos componentes genéticos e ambientais no refinamento do SN. Não são conhecidos quais os mecanismos que levam a estimulação ambiental a interagir com o crescimento exuberante do SN e quais os eventos que selecionam determinados circuitos em detrimento de outros. Busca-se saber como os nossos comportamentos cognitivos e emocionais podem ser explicados em função da atividade dos circuitos e como estes podem ser dinamicamente modificados, mesmo no estágio adulto.

A condição humana é bastante complexa e a tarefa de estudá-la impõe a integração de diferentes áreas do saber. Os estudos que foram apresentados neste trabalho buscaram contrapor evidências favoráveis a um entendimento de um cérebro plástico, altamente sensível ao ambiente. Esta parece ser a principal função do cérebro: as trocas e adaptação ao meio. Por esta razão, foi necessário explanar estudos que pudessem aprofundar como isso se dá em termos moleculares. A partir deles, fica mais nítido como a experiência sensorial pode alterar de forma dramática a estrutura e a função dos circuitos neurais no neocórtex em desenvolvimento.

A construção do self parece seguir uma rota ancestral de evolução, mas não pode prescindir de um contexto, social e histórico, em meio a condições materiais específicas. Tendo em vista os pontos discutidos nesse trabalho, reitera-se que nossos comportamentos, pensamentos e sentimentos 
são possibilitados pelas sinapses que surgem durante todo o desenvolvimento, mudando o curso das nossas vidas e a estimulação ambiental é parte crucial desse processo.

Este trabalho buscou apresentar estudos em neurociências, psicologia evolucionista e psicologia do desenvolvimento. A idéia norteadora foi a de evidenciar que dados empíricos, obtidos de maneira independente, em áreas de estudo diversas, parecem estar articulados. Com isso consolida-se um caminho para uma integração teórica necessária, que, espera-se, contribua para a compreensão do que nos torna humanos, no palco da natureza e da cultura.

\section{Referências}

Baillargeon, R. (1995). A model of physical reasoning in infancy. In C. Rovee-Collier \& L. P. Lipsitt (Eds.), Advances in infancy research (pp. 305-371). Norwood, NJ: Ablex.

Bliss, T. V. P., \& Lomo, T. (1973). Long lasting potentiation of synaptic transmission in the dentate area of the anaesthetized rabbit following stimulation of the perforant pathway. Journal of Physiology, 232, 331-356.

Carlén, M., Meletis, K., Barnabé-Heider, F., \& Frisén, J. (2006). Genetic visualization of neurogenesis. Experimental Cell Research, 312, 2851-2859.

Cosmides, L., \& Tooby, J. (2000). Evolutionary psychology and the emotions. In M. Lewis \& J. M. Haviland-Jones (Eds.), Handbook of emotions (2nd ed., pp. 3-134). New York: Guilford Press.

Cowan, M. W. (1979). The development of the brain. Scientific American, 241, 113-133.

Duchaine, B., Cosmides, L., \& Tooby, J. (2001). Evolutionary psychology and the brain. Current Opinion in Neurobiology, 11, 225-230.

Dupoux, E., Pallier, C., Kakehi, K., \& Mehler, J. (2001). New evidence for prelexical phonological processing in word recognition. Language and Cognitive Processing, 16, 491-505.

Edelman, G. M. (2003). Naturalizing consciousness: A theoretical framework. Proceedings of the National Academy of Sciences, 9, 5520-5524.

Gazzaniga, M., \& Heatherton, T. (2005). Ciência psicológica: Mente cérebro e comportamento. Porto Alegre, RS: ArtMed.

Hebb, D. (1949). The organization of behavior. New York: Wiley.

James, W. (1950). The principles of psychology (Vols. 1-2). New York: Henry Holt. (Original work published 1890)

Jessell, T. M., \& Sanes, J. R. (2000). Development: The decade of the developing brain. Current Opinion in Neurobiology, 10(5), 599-611.

Johnston, M. V. (2004). Clinical disorders of brain plasticity. Brain Development, 26, 73-80.

Jones, E. G. (2000). Neuroscience in the Modern Era. Neuroscience Newsletter, 31, 5-11.

Kandel, E. R. (2000). Cellular mechanisms of learning and the biological basis of individuality. In E. R. Kandel, J. H. Schwartz, \& T. M. Jessell (Eds.), Principles of Neural Sciences (pp. 1247-1279). New York: McGraw-Hill.

Kandel, E. R. (2001). The molecular biology of memory storage: A dialog between genes and synapses. Bioscience Reports, 21(5), 565-611.

Karmiloff-Smith, A. (1992). Beyond modularity: A developmental perspective on Cognitive Science. Cambridge, MA: The MIT Press.

Karmiloff-Smith, A., Plunkett, K., Johnson, M. H., Elman, J. L., \& Bates, E. A. (1998). What does it mean to claim something is innate? Response to Clark, Harris, Lightfoot and Samuels. Mind and Language, 13(4), 588-597.
Katz, L. C., \& Shatz, C. J. (1996). Synaptic activity and the construction of cortical circuits. Science, 274, 1133-1138.

Kotch, L. E., \& Sulik, K. K. (1992). Experimental fetal alcohol syndrome: Proposed pathogenic basis for a variety of associated facial and brain anomalies. American Journal of Medical Genetics, 44, 168-176.

Lametti, D. R., \& Mattar, A. A. G. (2006). Mirror neurons and the lateralization of human language. The Journal of Neuroscience, 26, 6666-6667.

Lamprecht, R., \& LeDoux, J. (2004). Structural plasticity and memory. Nature Neuroscience Reviews, 5, 45-53.

LeDoux, J. (2002). Synaptic self: How our brains become who we are. New York: Viking.

Leonardo, E. D., \& Hen, R. (2006). Genetics of affective and anxiety disorders. Annual Review of Psychology, 57, 117-137.

Lewis, M., \& Brooks-Gunn, J. (1979). Social cognition and the acquisition of self. New York: Plenum.

Matsuzaki, M., Honkura, N., Ellis-Davies, G. C. R., \& Kasai, H. (2004). Structural basis of long-term potentiation in single dendritic spines. Nature, 429, 761-766.

Matus, A. (2000). Actin-based plasticity in dendritic spines. Science, 290, 754-758.

Mead, G. H. (1934). Mind, self and society from the standpoint of a social behaviorist. Chicago: University Press of Chicago.

Meltzoff, A. N., \& Moore, M. K. (1994). Imitation, memory and the representation of persons. Infant Behavior and Development, 17, 83-99.

Oliva, A. D. (2004). A noção de estado inicial e concepções de desenvolvimento: Problemas e necessidade de definições empíricas dos termos. In M. L. Seidl de Moura (Ed.), O bebê do século XXI e a psicologia em desenvolvimento (pp. 61110). São Paulo, SP: Casa do Psicólogo.

Oliva, A. D., Otta, E., Ribeiro, F. L., Bussab, V. S., Lopes, F., Yamamoto, M. E., et al. (2006). Razão, emoção e ação em cena: A mente humana sob um olhar evolucionista. Psicologia: Teoria e Pesquisa, 22(1), 53-62.

Pinker, S. (2002). O instinto da linguagem: Como a mente cria a linguagem. São Paulo, SP: Martins Fontes.

Quartz, S. R., \& Sejnowski, T. J. (1997). The neural basis of cognitive development: A construtivist manifesto. Behavioral and Brain Sciences, 20, 537-596.

Ramachandran, V. S. (2004). A brief tour of consciousness. New York: Pi Press.

Rapoport, J. L., \& Gogtay, N. (2008). Brain neuroplasticity in health, hyperactive and psychotic children: Insights from neuroimaging. Neuropsychopharmacology, 33(1), 181-197.

Ridley, M. (2004). O que nos faz humanos: Gene, natureza e experiência. São Paulo, SP: Record.

Rochat, P., \& Striano, T. (1999). Social-cognitive development in the first year. In P. Rochat (Ed.), Early social cognition: Understanding others in the first months of life (pp. 3-34). Mahwah, NJ: Lawrence Erlbaum.

Rovee-Collier, C. K. (2000). Memory in infancy and early childhood. In E. Tulving \& F. I. M. Craik (Eds.), The Oxford handbook of memory (pp. 267-282). New York: Oxford University Press.

Sedikides, C., \& Skowronski, J. J. (1997). The symbolic self in evolutionary context. Personality and Social Psychology Review, 1, 80-102.

Seidl de Moura, M. L. (2005). Dentro e fora da caixa preta: A mente sob um olhar evolucionista. Psicologia: Teoria e Pesquisa, 21(2), 141-147. 
Seidl de Moura, M. L., \& Ribas, A. F. (2004). Evidências sobre características de bebês recém-nascidos: Um convite a reflexões teóricas. In M. L. Seidl de Moura (Ed.), O bebê do século XXI e a psicologia em desenvolvimento (pp. 21-60). São Paulo, SP: Casa do Psicólogo.

Slater, A., von der Schulenburg, C., Brown, E., Badenoch, M., Butterworth, G., Parsons, S., et al. (1998). Newborn infants prefer attractive faces. Infant Behavior and Development, 21, 345-354.

Spelke, E. (2000). Core knowledge. American Psychologist, 55, 1233-1243.

Tooby, J., \& Cosmides, L. (1995). The Psychological Foundations of Culture. In H. Barkow, L. Cosmides, \& J. Tooby (Eds.), The adapted mind: Evolutionary psychology and the generation of culture. New York: Oxford.

Turati, C., Simion, F., Milani, I., \& Umiltà, C. (2002). Newborns' preference for faces: What is crucial? Developmental Psychology, 38(6), 875-882.

Zito, K., \& Svoboda, K. (2002). Activity-dependent synaptogenesis in the adult mammalian cortex. Neuron 35 , 1015-1017. 